\title{
Review of worldwide experience and the European legislation related to groundwater pollution assessment. Pollution indices and criteria
}

\author{
Marinela Panayotova ${ }^{1}$, Nikolay Stoyanov ${ }^{l}$, Svetlana Bratkova ${ }^{1}$ \\ ${ }^{1}$ University of Mining and Geology „St. Ivan Rilski“, Sofia, Bulgaria; \\ e-mail: marichim@mgu.bg,nts@mgu.bg, s_bratkova@yahoo.com
}

\section{Преглед на световния опит и Европейското} законодателство, свързани с оценяване на замърсяването на подземните води. Показатели и критерии за замьрсяване Маринела Панайотова, Николай Стоянов, Светлана Браткова

Panayotova, M., N. Stoyanov, S. Bratkova. 2019. Review of worldwide experience and the European legislation related to groundwater pollution assessment. Pollution indices and criteria. Engineering Geology and Hydrogeology, 33, 51-66.

\begin{abstract}
A brief review of the European legislation related to groundwater protection and the legislation's transposition in Bulgaria has been made. The existence of the necessary regulatory framework for ensuring groundwater protection has been pointed out. The basic guidance documents that help to meet the requirements set out in the Water Framework Directive and its daughter directives are outlined. The worldwide scientific experience regarding introduction of different indices and criteria for assessing the groundwater pollution is briefly presented and discussed. The outlined indexes and criteria include the contamination factor $\left(C_{f}\right)$, the degree of contamination $\left(C_{d}\right)$, the modified degree of contamination $\left(m C_{d}\right)$, the contamination index $(C I)$, the metal pollution index $(M P I)$, the groundwater risk index $(G R I D)$, the pollution load index $(P L I)$, the heavy metal pollution index $(H P I)$, the heavy metal evaluation index $(H E I)$, the Nemerow index $(P I)$, the elemental (metal) contamination index $(E C I)$ and the overall metal contamination index $(M C I)$.
\end{abstract}

Keywords: European legislation, groundwater pollution indices, groundwater status, groundwater protection.

Резюме. Направен е кратьк преглед на Европейското законодателство, свързано с опазване на подземните води и транспонирането му в Р България. Посочени са основните ръководства, подпомагащи изпълнението на изискванията, поставени от Рамковата директива за водите и дъщерните ѝ директиви. Накратко е представен и дискутиран световният научен опит по отношение на оценката на замърсяването на подземните води с помощта на различни показатели и критерии на замърсяване. Описаните индекси и критерии включват фактора на замърсяване $\left(C_{f}\right)$, степента на замърсяване $\left(C_{d}\right)$, модифицираната степен на замърсяване $\left(m C_{d}\right)$, обобщения индекс на замърсяване $(C I)$, индекса на замърсяване с метали $(M P I)$, индекса на риска от замърсяване на подземни води (GRID), индекса на натоварване със замърсители $(P L I)$, индекса на замърсяване с тежки метали $(H P I)$, индекса за оценка на тежките метали 
$(H E I)$, индекса на Немеров (PI), индекса на замърсяване с даден елемент - метал $(E C I)$ и общия индекс на замърсяване с метали $(M C I)$.

Ключови думи: Европейско законодателство, показатели за замърсяване на подземни води, състояние на подземните води, опазване на подземните води.

\section{Въведение}

Подземните води са основен източник на питейна вода за човечеството и важен ресурс за световната икономика. Например те обезпечават водоснабдяването на $75 \%$ от жителите на Европейския съюз (ЕС), а около 44\% от общия подземен вододобив в Европа се използва за стопански нужди. Подземните води играят важна роля и в естествения хидроложки цикъл като базов ресурс за повърхностните водни системи. За повечето реки в Европа над 50\% от средния годишен отток е за сметка на подземен водоприток. В периоди на маловодие този дял може да нарасне до повече от 90\% (Европейска комисия, 2008). Подземните водни ресурси са от жизнено значение и за подземните екосистеми в карстовите или алувиалните водоносни хоризонти. Те поддържат почвената влага и много сухоземни растителни общности се подхранват пряко от водоносния хоризонт или от просмуканата почвена влага в ненаситената зона над нивото на подземните води. От тази гледна точка, качеството на подземните води влияе непосредствено не само върху състоянието на повърхностните води, екологичното разнообразие и устойчивото развитие на екосистемите, но има особено важно значение и за живота на хората.

Причините за замърсяване на подземните води могат да бъдат природни (геогенни) и антропогенни. Трябва да отбележим, че антропогенното въздействие може да бъде дълготрайно, т.е. замърсяване от преди няколко десетилетия, може и днес да влошава качеството на подземните води, а в някои случаи е възможно да стане заплаха за няколко поколения. Същевременно, подземните води, за разлика от повърхностните, са “скрит ресурс", за който мерките за превенция, мониторинг и възстановяване са доста по-трудни. При тях в много случаи е проблем адекватното локализиране, характеризиране и разбиране на въздействието от източника на замърсяване. Това често води до липса на достатъчно познания и/или доказателства за степента на замърсяване.

Споменатите по-горе факти са достатъчно убедителен аргумент за необходимостта от инструменти за оценяване качеството на подземните води и от специално внимание при набелязване на превантивни мерки срещу тяхното замърсяване. Голяма част от тези средства, дейности и мерки са залегнали както в Европейското законодателство, така и в Българската законова и нормативна уредба. За установяване и количествена оценка на обхвата и степента на замърсяване на подземните води в последните години от различни автори са публикувани и различни показатели, критерии и методични подходи, които успешно могат да бъдат прилагани, както в специализираните хидрохимични изследвания, така и в съвременната хидрогеоложка практика.

\section{Действащо Европейско законодателство в областта на подземните води}

Основополагащо значение има Рамковата директива за водите (РДВ) (Directive $2000 / 60 / E O, 2000$ ) и съответните иे изменения (последно изменение -Commission Directive 2014/101/EU, 2014). Рамковата директива за водите определя правила за спиране на процесите на влошаване състоянието на водните обекти в Европейския съюз и за постигане на статус „добро състояние“ за реките, езерата и подземните води на Европа. Включва мерки по: опазване на всички видове води (повърхностни, подземни, вътрешнотериториални и преходни); възстановяване на екосистемите в и около тези водни обекти; намаляване на замърсяването във водните обекти; гарантиране на устойчиво използване на водите от физически 
лица и предприятия. Прилага се от 22 октомври 2000 г. Държавите от ЕС трябваше да я включат в националното си законодателство до 22 декември 2003 г.

Основните нормативни документи, свързани с РДВ, пряко или косвено касаещи качеството и количеството на подземните води, са:

- Директива 2006/118/EO на Европейския парламент и на Съвета (Directive 2006/118/EC, 2006) за опазване на подземните води от замърсяване и влошаване на състоянието им и съответните ѝ изменения (Commission Directive 2014/80/EU, 2014).

- Директива 2007/60/EО на Европейския парламент и на Съвета относно оценката и управлението на риска от наводнения (Directive 2007/60/EC, 2007).

- Директива 2008/105/EO на Европейския парламент и на Съвета за определяне на стандарти за качество на околната среда в областта на политиката за водите (Directive 2008/105/EC, 2008) и съответните ѝ изменения (Directive 2013/39/EU, 2013).

- Съобщение на Комисията до Европейския парламент, Съвета, Европейския икономически и социален комитет и Комитета на регионите: План за опазване на водните ресурси на Европа (Commission, 2012).

- Доклад на Комисията до Европейския парламент и Съвета относно прилагането на РДВ и Директивата за наводненията (Commission, 2019).

- Директива на Съвета за опазване на водите от замърсяване с нитрати от селскостопански източници (Council Directive 91/676/EEC, 1991) и съответните ѝ изменения (последно изменение - Regulation (EC) No 1137/2008, 2008).

- Директива 2010/75/ЕС на Европейския парламент и на Съвета относно емисиите от промишлеността - комплексно предотвратяване и контрол на замърсяването (Directive 2010/75/EU, 2010).

- Директива 98/83/ЕО на Съвета относно качеството наводите, предназначени за консумация от човека (Council Directive 98/83/EC, 1998).

- Директива 2009/128/EО на Европейския парламент и на Съвета за създаване на рамка за действие на Общността за постигане на устойчива употреба на пестициди (Directive 2009/128/EC, 2009).

- Директива 2006/21/EO на Европейския парламент и на Съвета относно управлението на отпадъците от минно-добивните индустрии и за изменение на Директива 2004/35/EO (Directive 2006/21/EC, 2006).

- Директива 2009/90/EO на Комисията за определяне, съгласно Директива 2000/60/ЕО на Европейския парламент и на Съвета, на технически спецификации за химически анализ и мониторинг на състоянието на водите (Commission Directive 2009/90/EC, 2009).

- Директива 2013/39/ЕС на Европейския парламент и на Съвета за изменение на директиви 2000/60/EO и 2008/105/EО по отношение на приоритетните вещества в областта на политиката за водите (Directive 2013/39/EU, 2013), доколкото касае опосредствено замърсяването на подземните води чрез контакт / инфилтрация на повърхностни води.

- Решение за изпълнение ЕС 2015/495 на Комисията за определяне на списък за наблюдение на вещества в рамките на обхващащ целия Европейски съюз мониторинг в областта на политиката за водите, в съответствие с Директива 2008/105/EO (Commission implementation decision, 2015).

- Директива 2006/11/EC за замърсяването на водите с опасни вещества (Directive 2006/11/EC, 2006), доколкото касае опосредствено замърсяването на подземните води чрез контакт / инфилтрация на повърхностни води.

- Директива 91/271/ЕИО относно пречистването на отпадъчните води от населени места (Council Directive 91/271/EEC, 1991). 
Дьржавите членки на ЕС, Норвегия и Европейската комисия съвместно са разработили обща стратегия за подкрепа на прилагането на РДВ. Основната цел е да се постигне последователно и хармонично прилагане на РДВ. В рамките на тази стратегия са разработени методически практически ръководства по различни технически въпроси на РДВ. Документите, свързани с подземните води, са следните:

- Ръководен документ № 2. Идентификация на водните тела (Guidance Document No 2, 2003) - документът съдържа специфична информация за диференциране и идентифициране на подземните водни тела (ПВТ).

- Ръководен документ № 3. Анализ на натиска и въздействието (Guidance Document No. 3, 2003) - документът се фокусира върху анализа на натиска и въздействията върху водните тела. Посочени са особеностите при оценката и характеризирането на ПВТ. Предоставен е списьк с ключовите задачи за характеризиране на ПВТ, както и на приложим софтуер за моделиране и оценка.

- Ръководен документ № 15. Ръководство за мониторинг на подземните води (WFD CIS Guidance Document No 15, 2007) - документът изяснява проблемите на мониторинга на подземните води, свързани с количествения и химичен статус на водните тела, наблюдение на защитена зона или мониторинг, свързан с мерките за предотвратяване / ограничаване на замърсяването. Основният му фокус е върху изискванията на РДВ. Ръководството отговаря и на изискванията на дъщерната Директива за подземните води. Документът предоставя насоки за създаване на програми за мониторинг на подземните води. Програмите включват количествен и химичен (качествен) мониторинг за оценка на състоянието и тенденциите, мониторинг за допълнително характеризиране на ПВТ и определяне на целите на защитените зони за питейна вода.

- Ръководен документ № 16. Подземни води в защитени зони за питейна вода (WFD CIS Guidance Document No 16, 2006) - документьт изяснява аспектите на изискванията на РДВ за защитените територии, които се прилагат за подземните води, по-специално - изискванията за защитените зони за питейна вода; Осветлява проблеми, които могат да засегнат управлението на трансграничните водоносни хоризонти и водни тела.

- Ръководен документ № 17. Предотвратяване или ограничаване на преките и непреките отвеждания към подземни води (WFD CIS Guidance Document No 17,2007$)$ - документът предоставя насоки за прилагането на РДВ по отношение на задължението за предотвратяване или ограничаване на навлизането на всички неопасни (сьгласно РДВ) замърсители в подземните води.

- Ръководен документ № 18. Оценка на състоянието на подземните води и тенденциите (Guidance Document No 18, 2009) - документът предоставя практически насоки за: (а) Определяне на методологията за получаване на пределни стойности за замърсители (или групи от замърсители), които са свързани с натиска, водещ до поставяне на подземните водни тела в рискова ситуация; (б) Установяване на рамките за оценка на химичното и количествено състояние на водните тела на основата на пределните стойности и стандартите за качество; (в) Определяне на метод за идентифициране на екологично значими тенденции; (г) Изискванията за отчетност.

- Ръководен документ № 26. Ръководство за оценка на риска и приложение на концептуални модели за подземни води (Guidance Document No 26, 2010) - документът представя съгласуван подход за оценка на рисковете, причинени от различен натиск (дифузно и точково замърсяване на 
подземните води; водочерпене, свързано с количеството на подземните води) в различни мащаби, вариращи от локално ниво до мащаба на цялото ПВТ. Анексьт за дефиниране и разработване на концептуални модели за подземните води и примерът от анекс III са в основата на „Ръководство $26 a$ - Концептуални модели за подземните води“, одобрено от министьра на околната среда и водите на Р България на 10.10.2012 г.

\section{Действащо законодателство в Р България в областта на подземните води}

Законътзаопазванена околнатасреда(2002)-ЗООСенай-широкатазаконодателна рамка за съхраняването, подобряването на качеството и рационалното ползване на повърхностните и подземните води. Съгласно чл. 49 от ЗООС, опазването на земните недра при проучването и ползването на подземните води се извършва по ред, определен от Закона за водите. Законът за водите (1999) - ЗВ урежда собствеността и управлението на водите на територията на Р България като общонационален неделим природен ресурс и собствеността на водностопанските системи и съоръжения. Съгласно ЗВ се разработват програми за контролен и оперативен мониторинг на подземните води. Програмите включват наблюдения за химичното и количественото състояние на ПВТ. Зоните за защита на водите, характеризирани като водни тела в риск, се включват в програмите за оперативен мониторинг на повърхностните и подземните води.

Основните наредби, по които се извършва оценка за качеството и количеството на подземните води, са:

- Наредба № 1 (2007) за проучване, ползване и опазване на подземните води - тя регламентира специфичните изисквания за проучването и ползването на подземните и минералните води и опазването им от замърсяване и влошаване на техните качества. Наредбата определя реда за събиране на данни и информация за оценка на състоянието на ПВТ и риска от влошаване в резултат от човешката дейност. Наредбата въвежда в националното законодателство изискванията на Директива 2006/118/ЕО относно опазването на подземните води от замърсяване и влошаване на техните качества. Приложение 1 към чл. 10, ал. 2, т. 1 въвежда стандарти за качеството на подземните води.

- Наредба № 1 (2011) за мониторинг на водите - тя урежда реда и начина за планираненамониторингаизасъздаваненамрежитезамониторингнаводите на територията на страната, както и за изпълнение дейностите по тяхната експлоатация, поддръжка, комуникационно осигуряване и лабораторноинформационно обслужване. По отношение на подземните води цел на наредбата е осигуряване на нормативна основа за мониторинга и на зони за защита на водите, както и дефиниране на изискванията към програмите за мониторинг на подземните води. Наредбата определя мониторираните показатели, техническите спецификации за химичен анализ и мониторинг на състоянието на водите и установява минимални критерии за методите за анализ. Спрямо подземните води се прилага контролен и оперативен мониторинг на химичното състояние. На оперативен мониторинг подлежат само пунктове, където е определено лошо състояние на водите в ПВТ. Наредбата определя честотата на пробонабиране за различните видове показатели, характеризиращи качеството на водата.

- Наредба № 1 (2016) за одобряване на методика за прилагане на изключенията по чл. 1566 - 156 е от Закона за водите - целта на методиката е да осигури: (а) Преглед на основанията и условията за прилагане на изключение от целите за опазване на околната среда по чл. 156б-156е от 3В за постигане на добро състояние на водите и адаптиране на екологичните цели за специфични водни тела; (б) Прагматичен и приложим подход и 
инструменти за идентифициране на потенциалните ситуации за прилагане на изключения и за представяне на коректен и реалистичен анализ на всяка конкретна ситуация.

- Наредба № 2 (2007) за опазване на водите от замърсяване с нитрати от земеделски източници - тя урежда реда и начина за установяване, ограничаване и предотвратяване на замърсяването на повърхностните и подземните води с нитрати от земеделски източници и правата и задълженията на компетентните органи.

- Наредба № 3 (2000) за условията и реда за проучване, проектиране, утвърждаване и експлоатация на санитарно-охранителните зони (СО3) около водоизточниците и съоръженията за питейно-битово водоснабдяване и около водоизточниците на минерални води, използвани за лечебни, профилактични, питейни и хигиенни нужди

- Наредба № 9 (2001) за качеството на водата, предназначена за питейнобитови цели.

За улеснение при прилагането на Българското законодателство по отношение на подземните води Министерството на околната среда и водите (МОСВ) е разработило методичен подход за оценка на количественото състояние на подземните води (https://www.moew.government.bg/static/media/ups/tiny/ filebase/Water/PURB/Podhodi/GW_pdf_270716/GW_status_kolichestvo_final.pdf) и подход за оценка на химичното състояние на подземните води (https://www. moew.government.bg/static/media/ups/tiny/filebase/Water/ PURB/Podhodi/GW pdf_270716/GW-status_himichen_final.pdf). Двата документа са разработени в съответствие с изискванията на РДВ, Директива 2006/1 18/ЕО, Наредба № 1/2007 г., Наредба № 1/2011 г. и ръководни документи № 3, № 17, № 18 и № 26.

Съгласно първия документ ПВТ се определя в добро количествено състояние, когато са изпълнени два обобщени критерия: (1) Нивото на подземните води се лимитира от условието общият средно многогодишен добив на подземни води, включващ добива на база издадени от МОСВ разрешителни за водовземане и добива от кладенците за задоволяване на собствените потребности на гражданите, да не превишава разполагаемите водни ресурси на ПВТ; (2) Промените в нивото на подземните води, настьпили в резултат на осъществявания вододобив, не предизвикват временна или постоянна промяна в посоката на потока, включително на ограничени територии, които могат да доведат до: (а) непостигане на целите за свързаните повърхностни водни тела; (б) значимо влошаване състоянието на повърхностни водни тела; (в) значително увреждане на сухоземни екосистеми, зависещи пряко от ПВТ; (г) привличане (интрузия) на солени води или други замърсени води; (д) непрекъсната и ясно определена антропогенна тенденция за промяна в посоката на потока, която може да доведе до интрузия.

Според втория методичен документ химичното състояние на ПВТ се определя в две категории - „добро“ и „лошо“. След определяне на прагови стойности на показателите за качество на подземните води по описаните в същия документ стъпки, оценката се прави чрез последователно прилагане на няколко теста.

Първият тест „Обща оценка на химичното състояние на ПВТ“ е основен. Накратко технологията за неговото прилагане е следната:

За всеки наблюдаван показател в даден мониторингов пункт на съответното ПВТ се извършва статистическа обработка на редицата от данни за целия наблюдаван период, като за по-висока достоверност при последващата оценка се използва медианата вместо средноаритметичната стойност (при много къса редица методиката допуска и използване на средна стойност). Получените стойности за всеки показател се сравняват със съответните най-строги нормирани стойности (предварително определените за ПВТ прагови стойности или стандартите за качество, дефинирани в Наредба № 1/2007 г.). Ако статистически 
определената стойност е под нормираната, то водата в мониторинговия пункт по съответния показател е в „добро“ химично състояние. И обратно - ако е над праговата стойност (или над стандарта за качество), то химичното състояние на водата е „лошо“. При крайната оценка за района на мониторинговия пункт се приема, че: (а) ако по всички показатели водата е в ,добро“ състояние, то и общото химично състояние на водата в пункта е „добро“; (б) ако само по един показател състоянието е „лошо“, то и общото химично състояние се определя като ,лошо“.

При установено „лошо“ химично състояние се прави анализ на първичните хидрохимични данни за показателя (показателите), определящ(и) състоянието като „лошо”. Ако се прецени, че данните не притежават необходимата достоверност, показателят (показателите) може да се отхвърли(ят) при крайната оценка на състоянието на подземните води в пункта за мониторинг.

Ако по един или повече показатели в района на един или няколко мониторингови пункта състоянието е определено като „лошо“, се прави оценка на засегнатата площ в следната последователност: (а) Очертава се всеки засегнат от замърсяване участък от ПВТ, в който се включват площите, разположени между мониторинговите пунктове, в които са установени наднормени стойности и крьгови площи с радиус $1 \mathrm{~km}$ около всеки пункт, в който е установено превишение; (б) Изчислява се каква част от общата площ на ПВТ заема очертаната площ на всеки от засегнатите от замърсяване участъци, в \%; (в) Ако замърсената площ от ПВТ е по-малка от 20\% от общата площ на тялото или резултатите от описаните по-долу тестове 1 - 4 показват „добро“ състояние и не са установени тенденции за повишаване концентрациите на замърсителите, то и химичното състояние на ПВТ се оценява като „добро“; (г) Химичното състояние на ПВТ се оценява като „лошо“, когато (а) замърсената площ от ПВТ е по-голяма или равна на 20\% от общата площ или (б) замърсената площ е по-малка от 20\% от площта на ПВТ, но един или няколко от останалите тестове показват, че е влошено качеството на подземните води или са установени значими и устойчиви тенденции за повишаване на концентрациите на замърсителите и показателите на замърсяване.

Методичният подход предвижда последващо изпълнение и на други тестове, ако основният тест определя състоянието на ПВТ като „лошо“. В зависимост от обекта на въздействие и механизмите на замърсяване се прилага някой от следните четири теста:

- Тест 1: „Интрузия на солени и замърсени води“ - тестът се прилага само за тела, оценени в „лошо“ количествено състояние и заедно с това показали отклонения от изискванията за „добро“състояние по даден физикохимичен показател. С теста се проверява дали понижаването на водните нива и/или промените в структурата на филтрационното поле са довели до влошаване на качеството на водата в резултат на привличане на солени или замърсени води.

- Тест 2: „Значимо влошаване на екологичното или химичното състояние на повърхностните водни тела, причинено от пренос на замърсители от ПВТ“ - тестът отчита връзката повърхностни/подземни води и се прилага за участъци, в които е идентифицирана такава връзка. При установени отклонения от доброто състояние на подземните води в даден мониторингов пункт, попадащ в обхвата на такива участьци, се прави оценка на възможното влияние на замърсените подземни води върху качеството на хидравлично свързаните с тях повърхностни води.

- Тест 3: „Значимо влошаване на състоянието на земните екосистеми, зависещи от подземните води поради пренасяне на замърсители от ПВТ“ - тестът отчита дали е осигурено необходимото качество на подземните 
води за поддържане на екосистемите, зависещи от тях. Той се прилага за екосистеми, попадащи в районите на мониторинговите пунктове, оценени в ,лошо“ състояние по определен показател и попадащи в най-близките до повърхността подземни води. Извършва се оценка на вероятността влошеното качество на подземните води по определен/и показател/и да оказва отрицателно влияние върху статуса на екосистемата.

- Тест 4: „Влошаване качествата на подземните води, предназначени за питейно-битово водоснабдяване“ - тестът се прилага за ПВТ, в които са идентифицирани водовземни съоръжения/системи за питейно-битово водоснабдяване и които попадат в установените чрез първия основен тест райони с превишения на концентрацията на замърсителите.

След приключване на всички необходими тестове крайната оценка на състоянието на определените в риск ПВТ завършва с изследване на тенденциите за развитие на процесите на замърсяване, включващо статистически анализ на данните от контролния, оперативния и собствен мониторинг върху състава и качествата на подземните води, изпълняван в съответствие с действащата в Р България законова и нормативна база. Способите за определяне на тези тенденции и тяхното тълкуване са подробно разписани в предложения от МОСВ методичен подход.

\section{Кратьк преглед на световния научен опит по отношение на оценката на замърсяването на подземни води}

Решаването на задачите, поставени от Европейското и Българското законодателство, изисква научен подход за оценка на замърсяване на подземните води. Прегледът на световния научен опит води до извода, че при най-често използваните методи за оценка замърсяването на подземните води се използват следните показатели, индекси, категоризации и класификационни критерии.

\section{Фактор на замърсяване $\left(C_{f i}\right)$}

Показателят отчита въздействието на един замърсител и е въведен от Håkanson (1980):

$$
C_{f i}=C_{A i} / C_{r}
$$

където: $C_{A i}$ - аналитично определена концентрация на $i$-я елемент (осреднена от най-малко 5 броя анализи); $C_{r}$ - референтна стойност (фонова концентрация) на съответния елемент преди възникване на антропогенно въздействие.

Степен на замьрсяване $\left(C_{d}\right)$

Степента на замърсяване $C_{d}$ се дефинира с израза (Håkanson, 1980):

$$
C_{d}=\sum_{i=1}^{n} C_{f i}
$$

където: $C_{f i}$ - фактор на замърсяване, дължащо се на $i$-я елемент, $n$ - брой анализирани елементи (при Håkanson $n=8)$.

Факторите на замърсяване и съответната степен на замърсяване, категоризирани от Håkanson, са обобщени в таблица 1 .

Въведена е и друга дефиниция на фактора на замърсяване $C_{f}$ (Backman et al., 1998; Hoaghia et al., 2016; Yari, Sobhanardakani, 2016; Bodrud-Doza et al., 2016; Naseh et al., 2018), което води до промяна на смисъла и обхватите при категоризацията на замърсяването с помощта на $C_{d}$, а именно:

$$
C_{f i}=\frac{C_{A i}}{C_{N i}}-1
$$

където: $C_{N i}$ максимално допустима по нормативни документи концентрация за $i$-я елемент. 
При тази дефиниция на $C_{f}$, стойностите на $C_{d}$ са класифицирани в три категории, отразяващи нивото на замърсяване: ниско - при $C_{d}<1$, средно - при $1<C_{d}<3$ и високо - при $C_{d}>3$.

Таблица 1. Фактори на замърсяване и степен на замърсяване, категоризирани по Håkanson Table 1. Contamination factors and degree of contamination categorized by Håkanson

\begin{tabular}{|c|c|c|}
\hline Фактор на замърсяване $C_{f i}$ & Категория & $\begin{array}{c}\text { Степен на } \\
\text { замърсяване } C_{d}\end{array}$ \\
\hline$C_{f i}<1$ & Практически липсващо замърсяване & $C_{d}<8$ \\
\hline $1<C_{f i}<3$ & Умерено замърсяване & $8<C_{d}<16$ \\
\hline $3<C_{f i}<6$ & Значително замърсяване & $16<C_{d}<32$ \\
\hline$C_{f i}>6$ & Много високо замърсяване & $C_{d}>32$ \\
\hline
\end{tabular}

Забележка: Оценката, базирана на представените в таблица 1 критерии, е коректна, ако в изчисленията на $C_{d}$ са включени аналитично определените концентрации на тежките метали живак $(\mathrm{Hg})$, кадмий $(\mathrm{Cd})$, арсен $(\mathrm{As})$, мед $(\mathrm{Cu})$, олово $(\mathrm{Pb})$, хром $(\mathrm{Cr})$, цинк $(\mathrm{Zn})$ и полихлорираните бифенили (PCB - Polychlorinated biphenyl).

Обобщен индекс на замърсяване ( CI ), индекс на замърсяване по един замърсител $\left(C_{F i}\right)$, индекс на замърсяване сметали (MPI), индекс на риска от замърсяване на подземни води ( GRID)

Обобщеният индекс на замърсяване $C I$ се дава със зависимостта (Ramadan, Haruna, 2018):

$$
C I=\sum_{i=1}^{n} \frac{C_{F i}}{n}
$$

където: $C_{F i}$ е индексът на замърсяване по един замърсител, който се изчислява по формулата:

$$
C_{F i}=\frac{C_{A i}}{C_{M A C}}
$$

където: $C_{M A C}-$ максимално допустима концентрация.

Условно се приема, че водата е незамърсена при $C_{F i}<1$ и замърсена при $C_{F i}>$ 1 , като по-голямата стойност на $C_{F i}$ корелира с по-голямо замърсяване.

Индексьт на замърсяване $C I$ се използва за тристепенно категоризиране на водата - незамърсена вода $(C I<1)$, слабо замърсена вода $(1<C I<5)$ и замърсена вода $(C I>5)$. Някои автори прилагат зависимости (4) и (5) само за метализамърсители и наричат $C I$ индекс на замърсяване с метали MPI (Singh et al., 2014-2015).

Подобна класификация се прилага в щата Калифорния (САЩ), като $C I$ се нарича индекс на риска от замърсяване (GRID) - https://www.owp.csus.edu/grid/. Използваните в нея пет категории и техните граници са представени в таблица 2. Индексът GRID се прилага основно при оценка на подземни води, предназначени за питейно-битово водоснабдяване.

C цел опазване на живота и здравето на човека е предложено индексьт $C I$ $(G R I D)$ за замърсители извън групата на приоритетните да се дефинира с изчислия по формула (5) индекс $C_{F i}$. За приоритетни замърсители вместо максимално допустимата концентрация $C_{M A C}$ трябва да се използва фоновата концентрация на съответния замърсител (Belousova, 2006), което се покрива с предложения от Håkanson фактор на замърсяване - формула (1). 
Таблица 2. Степени на замърсяване на подземните води, категоризирани по индекса GRID Table 2. Degree of groundwater contamination categorized by GRID index

\begin{tabular}{|c|c|c|c|c|c|}
\hline $\begin{array}{c}\text { Диапазон на } \\
\text { индекса }\end{array}$ & $G R I D \leq 0.6$ & $\begin{array}{c}0.6<G R I D \\
<1.2\end{array}$ & $\begin{array}{c}1.2<G R I D \\
<1.8\end{array}$ & $\begin{array}{c}1.8<\text { GRID } \\
<2.8\end{array}$ & GRID $>2.8$ \\
\hline $\begin{array}{c}\text { Степен на } \\
\text { замърсяване }\end{array}$ & Няма & Слабо & Средно & Силно & $\begin{array}{c}\text { Много } \\
\text { силно }\end{array}$ \\
\hline
\end{tabular}

Забележка: Оценката, базирана на представените в таблица 2 критерии, е коректна, ако в изчисленията на GRID са включени аналитично определените концентрации 1,2,3-трихлорпропан (1,2,3 TCP), 1,2-дибромо-3-хлорпропан (DBCP), арсен (As), шествалентен хром $\left(\mathrm{Cr}^{\mathrm{VI}}\right)$, нитратен азот $(\mathrm{N})$, перхлорат $\left(\mathrm{ClO}^{-}\right)$, тетрахлоретен $(\mathrm{PCE})$, общо разтворени твърди съединения (TDS), трихлоретен (TCE), уран (U).

\section{Модифицирана степен на замърсяване $\left(\boldsymbol{m} C_{d}\right)$}

Показателят $m C_{d}$ е подобен на $C I$ и се дефинира с израза:

$$
m C_{d}=\sum_{i=1}^{n} \frac{C_{f i}}{n}
$$

където $n$ е броят на анализираните елементи.

Според Kaddour et al. (2017), прилагането на тази обобщена формула за изчисляване на $m C_{d}$ позволява включване на всички метали, които се анализират при едно конкретно изследване. Предложената от тях класификация на замърсяването на подземните води посредством $m C_{d}$ е представена в таблица 3.

Таблица 3. Категоризация на замърсяването посредством показателя $m C_{d}$ Table 3. Pollution categorization by using index $m C_{d}$

\begin{tabular}{|c|c|}
\hline Категория & Модифицирана степен на замърсяване $m C_{d}$ \\
\hline Практически липсва замърсяване & $m C_{d}<1.5$ \\
\hline Ниско ниво на замърсяване & $1.5<m C_{d}<2$ \\
\hline Умерено ниво на замърсяване & $2<m C_{d}<4$ \\
\hline Високо ниво на замърсяване & $4<m C_{d}<8$ \\
\hline Много високо ниво на замърсяване & $8<m C_{d}<16$ \\
\hline Екстремно високо на замърсяване & $16<m C_{d}<32$ \\
\hline Ултра-високо ниво на замърсяване & $m C_{d}>32$ \\
\hline
\end{tabular}

Забележка: Оценката, базирана на представените в таблица 3 критерии, е коректна, ако в изчисленията на $m C_{d}$ са включени аналитично определените концентрации на тежките метали кадмий $(\mathrm{Cd})$, желязо $(\mathrm{Fe})$, мед $(\mathrm{Cu})$, олово $(\mathrm{Pb})$, хром $(\mathrm{Cr})$, цинк $(\mathrm{Zn})$.

\section{Индекс на натоварване със замърсители (PLI)}

Този индекс дава интегрална индикация за общото ниво на замърсяване с тежки метали в определена проба (обект). Той е функция на факторите на замърсяване $C_{f}$, изчислени по формула (1) за всеки от изследваните показатели (Singh et al., 2014-2015; Kaddour et al., 2017):

$$
P L I=\left(C_{f 1} \times C_{f 2} \times C_{f 3} \times \ldots \ldots \ldots \ldots C_{f n}\right)^{1 / n}
$$

При оценката се използва дихотомна скала - водата е незамърсена при $P L I>$ 1 и замърсена при $P L I<1$.

\section{Индекс на замърсяване с тежки метали (НРI)}

Индексът HPI също интегрално характеризира качеството на водата по отношение на тежките метали. Представя се с израза (Mohan et al., 1996; Yankey et al., 2013; Hoaghia et al., 2016, Sobhanardakani et al., 2016; Bodrud-Doza et al., 2016; Naseh et al., 2018): 


$$
H P I=\frac{\sum_{i=1}^{n} W_{i} Q_{i}}{\sum_{i=1}^{n} W_{i}}
$$

където: $Q_{i}$ - под-индекс на $i$-тия елемент-замърсител, $W_{i}$ - относителна тежест на замърсителя $i, n-$ брой анализирани замърсители.

Много често $W_{i}$ се изчислява като стойност, обратно пропорционална на $C_{M A C}$ на съответния замърсител. Под-индексът $Q_{i}$ на замърсителя $i$ се изчислява по формулата:

$$
Q_{i}=\sum_{i=1}^{n} \frac{\left|M_{i}-I_{i}\right|}{S_{i}-I_{i}} \times 100
$$

където: $M_{i}$ - аналитично определена концентрация на тежкия метал, $I_{i}-$ идеална концентрация (обикновено се приема за 0, т.е. като не се въвежда в законодателството на повечето държави) на $i$-тия замърсител, $S_{i}-$ нормирана в стандарта за качество стойност.

Оценката на замърсяването с тежки метали по HPI използва тристепенна скала - няма замърсяване $(H P I<100)$, замърсяване на границата на риска $(H P I=$ $100)$ и високо замърсяване $(H P I>100)$.

\section{Индекс за оценка на тежките метали (НЕI)}

Индексът за оценка на тежки метали HEI е въведен за категоризиране качеството на водата с акцент върху тежките метали във водните проби. Изчислява се посредством предложената в (Hoaghia et al., 2016; Sobhanardakani et al., 2016) формула:

$$
H E I=\sum_{i=1}^{n} \frac{H_{c i}}{H_{M A C i}}
$$

където: $H_{c i}$ - аналитично определена концентрация на $i$-тия метал във водната проба; $H_{\text {MACi }}$ - максимално допустима концентрация на $i$-тия тежък метал замърсител, нормирана в съответното законодателство.

Според Hoaghia et al. (2016) индексът HEI класифицира замърсяването на водата в 3 категории според съдържанието на тежки метали: ниско (HEI < $40)$, умерено $(40<H E I<80)$ и високо $(H E I>80)$. Други автори предлагат като гранична стойност на замърсяване $H E I=100$ (Prasad et al., 2001; Sobhanardakani et al., 2016). Различията в посочените категоризиращи стойности на $H E I$ са свързани с броя на изследваните замърсители.

\section{Индекс на Немеров ( PI)}

Въведен е за оценка на общото въздействие при замърсяване с различни тежки метали (Kapelewska et al., 2019). За всеки от съдържащите се в анализираните водни проби тежки метали, т.е. за $i$-тия потенциален замърсител индексьт на Немеров $(P I)$ се изчислява по формулата:

$$
P I=\left[\frac{\left(C_{F i \text { avg }}^{2}+C_{F i \max }^{2}\right)}{2}\right]^{\frac{1}{2}}
$$

където: $C_{F i \text { avg }}$ - средна стойност на индекса $C_{F i}$ за всички изследвани проби, $C_{F i}$ max - максимална стойност на индекса $C_{F i}$ за всички проби, $C_{F i}-$ индекс на замърсяване за $i$-тия потенциален замърсител (тежьк метал), определен по формула (5). 
След изчисляване на индекса на Немеров за всеки тежък метал се определя и степента на неговото въздействие въз основа на предложената четиристепенна скала - няма отрицателно въздействие $(P I<0.7)$, много слабо въздействие $(0.7$ $<P I<1)$, слабо въздействие $(1<P I<2)$, средно въздействие $(2<P I<3)$, силно въздействие $(P I>3)$.

\section{Индекс на замърсяване с даден елемент - метал (ЕСI) и общ индекс на замърсяване с метали (МСI)}

Посредством индексите $E C I$ и $M C I$ може да се оцени степента на замърсяване с даден метал или общото метално замърсяване, като се отчитат регистрираните превишения над фоновите стойности (Singh et al., 2014-2015). Формулите за изчисляване на двата индекса имат вида:

$$
\begin{gathered}
E C I=\frac{C_{m i}-B_{m i}}{B_{m i}} \\
M C I=\sum_{i=1}^{n} \frac{C_{m i}-B_{m i}}{B_{m i}}
\end{gathered}
$$

където: $C_{m i}$ - измерена концентрация на $i$-тия метал, $B_{m i}-$ фонова концентрация на $i$-тия метал в изследвания район, $n-$ брой на изследваните метали $(i=1,2$, ...... $n)$.

Индексът MCI е предложен с цел оценяване общото замърсяване с тежки метали $(\mathrm{Cu}, \mathrm{Pb}, \mathrm{Zn}, \mathrm{Cd})$ в скала с четири класификационни диапазона, определящи следните степени на замърсяване - много слабо $(0<M C I<5)$; силно $(25<M C I<$ $50)$; много силно $(25<M C I<50)$; екстремно $(M C I>100)$.

\section{Заключение}

Направеният преглед на Европейското законодателство разкрива, че през последните две десетилетия са приети и в момента действат голям брой документи, осигуряващи защитата и опазването на подземните води. Европейското законодателство е в достатъчна степен транспонирано и в действащата в Р България законова и нормативна база. Уредено е и използването на основните методически ръководства, разработени на ниво ЕС, с цел улесняване прилагането на РДВ.

Прегледът на световния научен опит по отношение на оценката на замърсяването на подземните води показва, че се използват различни показатели за замърсяване. Повечето от тях дефинират като основен показател за замърсяване от един елемент, йон или съединение съотношението между аналитично определената (осреднена от мониторинг) концентрация на този замърсител и нормативно определена за него концентрация (MAC, фонова). Сумата от тези съотношения или модифицираните ѝ спрямо броя или относителните тегла на замърсителите стойности се разглеждат като количествени показатели за определяне на общото замърсяване на подземните води. За установяване на наличие и/или оценка степента на замърсяване различните автори предлагат различни категории и диапазони на класификационните критерии. Най-общо (но не във всички публикации) тези стойности са съобразени както с броя разглеждани замърсители, така и с геоложките особености в съответната държава, а най-вероятно и с вече натрупаното антропогенно замърсяване и границата на социална поносимост. Използването на модифицирани индекси, получени чрез разделяне на брой замърсители или въвеждане на относителни тегла за различните замърсители, би трябвало по-внимателно да дефинира диапазоните на различните категории замърсяване. Смятаме, че дефинициите, терминологията и класификацията, въведени от Håkanson (1980), са достатъчно 
строги и ефективни за класифициране на замърсяването с цел опазване на подземните води, като не бива да се забравя, че граничните стойности, дефиниращи отделните степени на замърсяване, трябва да бъдат съобразени с анализирания брой замърсители.

\section{Благодарности}

Статията се базира на непубликувани авторски разработки, изпълнени в рамките на Националната научна програма „Опазване на околната среда и намаляване на рисковете от нежелани събития и природни бедствия“, одобрена с Решение на Министерския съвет № 577 / 17.08.2018 г. и подкрепена от Министерството на образованието и науката, Р България (Споразумение № DO-230 / 06-12-2018).

\section{Използвани нормативни документи и ръководства Used legislation and Guidance Documents}

Европейска комисия. 2008. Опазване на подземните води в Европа, Люксембург - Служба за официални публикации на Европейската Общност, 35 стр.

Закон за водите, ДВ. бр. 67 от 27 юли 1999 г., последно изм. и доп. ДВ. бр. 103 от 13 декември 2018 г.

Закон за опазване на околната среда, ДВ. бр. 91 от 25 септември 2002 г., последно изм. и доп. ДВ. бр. 36 от 3 май 2019 г.

Наредба № 1 от 1.07.2016 г. за одобряване на Методика за прилагане на изключенията по чл. 1566 - 156е от Закона за водите, ДВ., бр. 55 от 19.07.2016 г.

Наредба № 1 от 10.10.2007 г. за проучване, ползване и опазване на подземните води, ДВ., бр. 87 от 30.10.2007 г., последно изм. и доп. ДВ., бр. 102 от 23.12.2016 г.

Наредба № 1 от 11.04.2011 г. за мониторинг на водите, ДВ., бр. 34 от 29.04.2011 г., последно изм. и доп. ДВ., бр. 20 от 15.03.2016 г.

Наредба № 2 от 13.09.2007 г. за опазване на водите от замърсяване с нитрати от земеделски източници, ДВ., бр. 27 / 11.03.2008 г., изм. и доп. ДВ., бр. 97 / 9.12.2011 г.

Наредба № 3 от 16.10.2000 г. за условията и реда за проучване, проектиране, утвърждаване и експлоатация на санитарно-охранителните зони около водоизточниците и съоръженията за питейно-битово водоснабдяване и около водоизточниците на минерални води, използвани за лечебни, профилактични, питейни и хигиенни нужди, ДВ., бр. 88 от 27.10.2000 г.

Наредба № 9 от 16.03.2001 г. за качеството на водата, предназначена за питейнобитови цели, ДВ., бр. 30 от 28.03.2001 г, последно изм. и доп. ДВ., бр. 102 от 12.12.2014 г.

Commission Directive 2009/90/EC of 31 July 2009 laying down, pursuant to Directive 2000/60/EC of the European Parliament and of the Council, technical specifications for chemical analysis and monitoring of water status. OJ L 201, 1.8.2009, 36-39.

Commission Directive 2014/101/EU of 30 October 2014 amending Directive 2000/60/ EC of the European Parliament and of the Council establishing a framework for Community action in the field of water policy. OJ L 311, 31.10.2014, 32-35.

Commission Directive 2014/80/EU of 20 June 2014 amending Annex II to Directive 2006/118/EC of the European Parliament and of the Council on the protection of groundwater against pollution and deterioration. OJ L 182, 21.6.2014, 52-53.

Commission implementation decision (EU) 2015/495 of 20 March 2015 establishing a watch list of substances for Union-wide monitoring in the field of water policy pursuant to Directive 2008/105/EC of the European Parliament and of the Council. OJ L 78, 24.3.2015, 40-42. 
Commission. 2012. Communication from the European Commission to the European parliament, the Council, the European Economic and Social Committee and the Committee of regions , A Blueprint to Safeguard Europe's Water Resources. 14.11.2012. COM (2012) 673 final, 24 p.

Commission. 2019. Report from the Commission to the European Parliament and the Council on the implementation of the Water Framework Directive (2000/60/EC) and the Floods Directive (2007/60/EC). Brussels, 26.2.2019. COM(2019) 95 final, $11 \mathrm{p}$.

Council Directive 91/271/EEC of 21 May 1991 concerning urban waste water treatment. OJ L 135, 30.5.91, 40-51.

Council Directive 91/676/EEC of 12 December 1991 concerning the protection of waters against pollution caused by nitrates from agricultural sources. OJ L 375 , 31.12.1991, 1-8.

Council Directive 98/83/EC of 3 November 1998 on the quality of water intended for human consumption. OJ L 330, 5.12.1998, 32-54.

Directive 2000/60/EC of the European Parliament and of the Council of 23 October 2000 establishing a framework for Community action in the field of water policy. OJ L 327, 22.12.2000, 1-73.

Directive 2006/11/EC of the European Parliament and of the Council of 15 February 2006 on pollution caused by certain dangerous substances discharged into the aquatic environment of the Community. OJ L 64, 4.3.2006, 52-59.

Directive 2006/118/EC of the European Parliament and of the Council of 12 December 2006 on the protection of groundwater against pollution and deterioration. $O J L$ $372,27.12 .2006,19-31$.

Directive 2006/21/EC of the European Parliament and of the Council of 15 March 2006 on the management of waste from extractive industries and amending Directive 2004/35/EC. OJ L 102, 15-29.

Directive 2007/60/EC of the European Parliament and of the Council of 23 October 2007 on the assessment and management of flood risks. OJ L 288, 6.11.2007, 27-34.

Directive 2008/105/EC of the European Parliament and of the Council of 16 December 2008 on environmental quality standards in the field of water policy, amending and subsequently repealing Council Directives 82/176/EEC, 83/513/EEC, 84/156/ EEC, 84/491/EEC, 86/280/EEC and amending Directive 2000/60/EC of the European Parliament and of the Council. OJ L 348, 24.12.2008, 84-97.

Directive 2009/128/EC of the European Parliament and of the Council of 21 October 2009 establishing a framework for Community action to achieve the sustainable use of pesticides. OJ L 309, 24.11.2009, 71-85.

Directive 2010/75/EU of the European Parliament and of the Council of 24 November 2010 on industrial emissions (integrated pollution prevention and control). $O J L$ 334, 17.12.2010, 17-119.

Directive 2013/39/EU of the European Parliament and of the Council of 12 August 2013 amending Directives 2000/60/EC and 2008/105/EC as regards priority substances in the field of water policy. OJ L 226, 24.8.2013, 1-17.

Guidance Document No 18, Guidance on groundwater status and trend assessment, 2009. Luxembourg: Office for Official Publications of the European Communities, $84 \mathrm{p}$.

Guidance Document No 2, Identification of Water Bodies, 2003. Luxembourg: Office for Official Publications of the European Communities, $28 \mathrm{p}$.

Guidance Document No 26 Guidance on risk assessment and the use of conceptual 
models for groundwater, 2010. Luxembourg: Office for Official Publications of the European Communities, 70 p.

Guidance Document No 3, Analysis of Pressures and Impacts, 2003. Luxembourg:

Office for Official Publications of the European Communities, $157 \mathrm{p}$.

https://www.moew.government.bg/static/media/ups/tiny/filebase/Water/PURB/

Podhodi/GW_pdf_270716/GW_status_kolichestvo_final.pdf (accessed on 29.11.2019).

https://www.moew.government.bg/static/media/ups/tiny/filebase/Water/PURB/

Podhodi/GW_pdf_270716/GW-status_himichen_final.pdf) (accessed on

29.11.2019).

https://www.owp.csus.edu/grid/ (accessed on 10.10.2019).

Regulation (EC) No 1137/2008 of the European Parliament and of the Council of 22 October 2008. OJ L 311, 21.11.2008, 1-2.

WFD CIS Guidance Document No 15, Monitoring Guidance for Groundwater. 2007.

Luxembourg: Office for Official Publications of the European Communities, $54 \mathrm{p}$.

WFD CIS Guidance Document No 16, Groundwater in Drinking Protected Areas. 2006. Luxembourg: Office for Official Publications of the European Communities, $36 \mathrm{p}$.

WFD CIS Guidance Document No 17, Prevention or limitation of direct and indirect inputs in groundwater, 2007. Luxembourg: Office for Official Publications of the European Communities, 40 p.

\section{Литература}

\section{References}

Backman, B., D. Bodis, P. Lahermo, S. Rapant, T. Tarvainen. 1998. Application of a groundwater contamination index in Finland and Slovakia. Environ Geol., 36(12), 55-64.

Belousova, A. 2006. Indicators and indexes of groundwater quality sustainability. Sustainability of Groundwater Resources and its Indicators (Proc. Symposium S3, Seventh IAHS Scientific Assembly at Foz do Iguaçu, Brazil, April 2005), IAHS Publ., 302, 21-28.

Bodrud-Doza, Md., A.R.M. Towfiqul Islam, F. Ahmed, S. Das, N. Saha, M. Safiur Rahman. 2016. Characterization of groundwater quality using water evaluation indices, multivariate statistics and geostatistics in central Bangladesh. Water Science, 30, 19-40.

Håkanson, L. 1980. An ecological risk index for aquatic pollution control. A sedimentological approach. Water Research, 14, 975-1001.

Hoaghia, M.A., C. Roman, E.D. Kovacs, C. Tanasella, D. Ristou. 2016. The evaluation of the metal contamination of drinking water sources from Medias town, Romania using the metal pollution indices. Studia UBB Chemia, LXI, 3, Tom II, 461-471.

Kaddour, K., M. Smail, B. Hocine, A. Bouzaza, B. E. Hacen. 2017. Assessment of heavy metal pollution due to the lead-zinc mine at the Ain Azel area (northeast of Algeria). E3 Journal of Environmental Research and Management, 8 (1), 1-11.

Kapelewska, J., U. Kotowska, J. Karpińska, A. Astel, P. Zieliński, J. Suchta, K. Algrzym. 2019. Water pollution indicators and chemometric expertise for the assessment of the impact of municipal solid waste landfills on groundwater located in their area. Chemical Engineering Journal, 359, 790-800.

Mohan, S.V., P. Nithila, S.J. Reddy. 1996. Estimation of heavy metals in drinking water and development of heavy metal pollution index. J. Environ. Sci. Health Part A, 31, 283-289. 
Naseh, M.R.V., R. Noori, R. Berndtsson, J. Adamowski, E. Sadatipour. 2018. Groundwater pollution sources apportionment in the Ghaen Plain, Iran. Int. J. Environ. Res. Public Health, 15, 172, 18 p.

Prasad, B., J. Bose. 2001. Evaluation of the heavy metal pollution index for surface and spring water near a limestone mining area of the lower Himalayas, Environmental Geology, 41(1-2), 183-188.

Ramadan, J.A., A.I. Haruna, 2018. Assessment of heavy metal contamination in surface and groundwater resources using pollution indices in parts of Barkin Ladi, North Central Nigeria. IOSR Journal of Applied Geology and Geophysics, 6(6), 25-40.

Singh, P.K., P. Verma, A.K. Tiwari, S. Sharma, P. Purty. 2014-2015. Review of various contamination index approaches to evaluate groundwater quality with geographic information system (GIS). International Journal of ChemTech Research CODEN (USA), 7(4), 1920-1929.

Sobhanardakani, S., A.R. Yarib, L. Taghavic, L. Tayebi. 2016. Water quality pollution indices to assess the heavy metal contamination, case study: groundwater resources of Asadabad Plain in 2012. Arch Hyg Sci, 5(4), 221-228.

Yankey, R.K., J.R. Fianko, S. Osae, E.K. Ahialey, A.E. Duncan, D.K. Essuman, J.K. Bentum. 2013. Evaluation of heavy metal pollution index of groundwater in the Tarkwa mining area, Ghana. Elixir Pollution, 54, 12663-12667.

Yari, A.R., S. Sobhanardakani. 2016. Water quality assessment of groundwater resources in Qaleeh Shahin Plain based on $C_{d}$ and HEI. Quarterly of International Archives of Health Sciences, 3(3), 101-106.

Постьпила: 22.10 .2019

Received: 22 October 2019

Приета: 11.11.2019

Accepted: 11 November 2019 